\title{
Editorial: Non Genomic Actions of Thyroid Hormones in Cancer
}

\author{
Paul J. Davis ${ }^{1 *}$, Osnat Ashur-Fabian ${ }^{2}$, Sandra Incerpi ${ }^{3}$ and Shaker A. Mousa ${ }^{1}$ \\ ${ }^{1}$ Pharmaceutical Research Institute, Albany College of Pharmacy and Health Sciences, Rensselaer, NY, United States, \\ ${ }^{2}$ Department of Human Molecular Genetics and Biochemistry, Sackler School of Medicine, Tel Aviv University, Tel Aviv, Israel, \\ ${ }^{3}$ Department of Sciences, University Roma Tre, Rome, Italy
}

Keywords: integrin $\alpha \mathrm{v} \beta 3$, angiogenesis, anti-apoptosis, thyroxine, signal transduction, driver genes, tumor microenvironment, tetrac

\section{Editorial on the Research Topic}

\section{Non Genomic Actions of Thyroid Hormones in Cancer}

\section{OPEN ACCESS}

Edited and reviewed by: Antonino Belfiore,

Department of Clinical and Experimental Medicine, University of

Catania, Italy

*Correspondence: Paul J. Davis pdavis.ordwayst@gmail.com

Specialty section: This article was submitted to Cancer Endocrinology, a section of the journal Frontiers in Endocrinology

Received: 17 October 2019 Accepted: 20 November 2019 Published: 04 December 2019

Citation: Davis PJ, Ashur-Fabian O, Incerpi S and Mousa SA (2019) Editorial: Non

Genomic Actions of Thyroid Hormones in Cancer.

Front. Endocrinol. 10:847. doi: 10.3389/fendo.2019.00847
The molecular basis of the actions of thyroid hormone requires cellular uptake and liganding of the hormones by specific receptors in the cell nucleus and consequent expression of certain genes (1). That another panel of thyroid hormone receptors might allow iodothyronines to act without entering the cell appeared to be unlikely until a structural protein of the plasma membrane of rapidly dividing endothelial cells and of cancer cells $(1,2)$ was found to have a discrete receptor for thyroid hormone analogs. This receptor is on the extracellular domain of integrin $\alpha \mathrm{v} \beta 3$. It enables thyroid hormone stimulation of tumor cell proliferation, of tumor-linked angiogenesis, of tumor cell defense mechanisms, e.g., anti-apoptosis, and, apparently, of chemoresistance and radioresistance (Cayrol et al.; Davis et al.; Krashin et al.). A series of eight publications in a recent issue of Frontiers in Endocrinology is devoted to "Integrin $\alpha \mathrm{v} \beta 3$, non-peptide hormones and cancer" (Ashur-Fabian et al.; Cayrol et al.; Chin et al.; Davis et al.; Gionfra et al.; Hercbergs; Krashin et al.; Uzair et al.).

This previously unrecognized set of mechanisms of actions of thyroid hormones-initiated at the cell surface-has clinical implications (Hercbergs). The principal ligand for the hormone receptor on $\alpha \mathrm{v} \beta 3$ is L-thyroxine (T4) [(2), Davis et al.]. 3,5,3'-triiodo-L-thyronine (T3) (Uzair et al.) and reverse T3 (rT3) (Davis et al.) may have limited actions at the integrin, but Hercbergs has shown that pharmacological elimination of host $\mathrm{T} 4$ and substitution of $\mathrm{T} 3$ can serve to arrest tumor growth.

Transcription of an extensive panel of genes may be differentially regulated by $\mathrm{T} 4$ at its receptor on $\alpha v \beta 3$ of cancer cells (Cayrol et al.; Davis et al.); these include driver genes and genes involved in signal transduction (2), as well as the processes of angiogenesis (Cayrol et al.) and apoptosis [(2), Davis et al.] mentioned above, and epithelial-mesenchymal transition (EMT) (Uzair et al.) and the state of cellular actin (Uzair et al.).

The Frontiers in Endocrinology papers on $\alpha \mathrm{v} \beta 3$ and thyroid hormone also broaden the spectrum of cancers subject to control from this site. The growth of melanoma, particularly that of the eye, may be arrested via tetraiodothyroacetic acid (tetrac), a deaminated T4 analog that inhibits T4 actions at the integrin (Ashur-Fabian et al.). Proliferation of T cell lymphoma cells and angiogenesis at sites of lymphoma xenografts are subject to regulation via $\alpha v \beta 3$ (Cayrol et al.). Interestingly, $K-R A S$ status (wild vs. mutant) in human colorectal cancer (CRC) cells alters the abundance of heterodimeric $\alpha v \beta 3$ protein, but the relatively low threshold for tetrac/integrin activity at the integrin is unchanged by $K-R A S$ status and tetrac and chemically modified tetrac are equally effective in mutant and wild-type CRC (Chin et al.). 
It is important to note that normal, non-malignant cells express reduced quantities of $\alpha v \beta 3$ and the conformation of the integrin - a reflection of its state of activation (2) - is such that its signaling functions appear to be limited. Integrin $\alpha v \beta 3$ is one of the more than two dozen heterodimeric integrins that are structural proteins of the plasma membrane, serving a variety of functions by interacting with proteins and other cells in the immediate microenvironment. The microenvironment specific for $\alpha v \beta 3$ is extracellular matrix proteins (vitronectin, fibronectin, osteopontin, etc., containing the Arg-Gly-Asp [RGD] sequence) and various growth factor receptors (1). In a single cell, $\alpha \mathrm{v} \beta 3$ may also interact with adjacent vascular growth factor receptors. All such interactions in the immediate cellular environment may cause $\alpha v \beta 3$ and other integrins to activate intracellular signal transduction pathways with specific downstream consequences in terms of gene expression and cell function. We have not identified other integrins to contain thyroid hormone receptor sites (HY Lin: unpublished observations).

\section{REFERENCES}

1. Cheng SY, Leonard JL, Davis PJ. Molecular aspects of thyroid hormone actions. Endocr Rev. (2010) 31:139-70. doi: 10.1210/er.2009-0007

2. Davis PJ, Goglia F, Leonard JL. Nongenomic actions of thyroid hormone. Nat Rev Endocrinol. (2016) 12:111-21. doi: 10.1038/nrendo.2015.205

Conflict of Interest: The authors declare that the research was conducted in the absence of any commercial or financial relationships that could be construed as a potential conflict of interest.
The significance of the recognition of the existence of the receptor for thyroid hormone and perhaps for other non-peptide hormones includes: (1) the receptors are new therapeutic targets for which ligands already exist, e.g., tetrac or chemically modified tetrac as an antagonist of T4; (2) scanning of tumors is feasible with radiolabeled T4, modified structurally so that it does not enter the cells, and (3) drug delivery to tumors with tetrac coupled to a drug-binding nanoparticle, such as poly-lactic-co-glycolic acid, is possible.

In conclusion, it is clear that thyroid hormone as T4 can support cancer growth via cell surface $\alpha v \beta 3$. Exploitation of these receptors may have useful therapeutic consequences.

\section{AUTHOR CONTRIBUTIONS}

PD drafted the editorial. All authors contributed to manuscript revision, read, and approved the submitted version.

Copyright (c) 2019 Davis, Ashur-Fabian, Incerpi and Mousa. This is an open-access article distributed under the terms of the Creative Commons Attribution License (CC $B Y)$. The use, distribution or reproduction in other forums is permitted, provided the original author(s) and the copyright owner(s) are credited and that the original publication in this journal is cited, in accordance with accepted academic practice. No use, distribution or reproduction is permitted which does not comply with these terms. 